\title{
Culture, Health, and Nursing: An Overview
}

\author{
Jestoni Dulva Maniago, PhD, DNS* \\ Department of Nursing, College of Applied Medical Sciences, Majmaah University, 11952, Saudi Arabia \\ *Corresponding Author \\ Jestoni Dulva Maniago
}

Article History

Received: 13.06.2020

Accepted: 22.06.2020

Published: 25.06.2020

\begin{abstract}
This paper presents the relevance and interplay of health, culture and nursing. It has long been considered that health and culture plays an important role in the practice of nursing. The historical development of health and culture is reviewed with emphasis on nurse scholars and anthropologists who have addressed culture as an area of inquiry. The interplay of health, culture and nursing have broad implications for theory development and in the advancement of nursing science.
\end{abstract}

Keywords: Caring, culture, health, nursing science, theory development.

\section{INTRODUCTION}

In healthcare delivery system, the nurse interacts with people of various cultural experiences. People may share similar cultural beliefs or have different perspective and varied health inclinations to meet their health care needs. Acknowledging and adjusting to the cultural requirements of the client and significant others is an important component of nursing care. To plan and deliver culturally competent care, the nurse must understand the definitions of culture and cultural competence and the various aspects of culture that should be explored for each client [1].

Cultural awareness and understanding are required in cultural competent care to support nursing caring of people from diverse cultural backgrounds. Culture affects not only the health care practices but also the perception of both nurse and client. It is a significant aspect that a nurse should be knowledgeable about the culture and ethnicity of his client such as the client's traditions and values. Becoming aware of how culture influences individual behavior and thinking allows the nurse to plan the best care for his clients. To provide a culturally-sensitive nursing interventions to clients, awareness of the rules of interactions within a specific cultural group, such as communication patterns and customs, division of roles in the family unit, and spirituality are required [1]. Additionally, nurse's awareness of his own attitudes and tendencies to different cultural groups allows the nurse to provide genuine care and concern [2].

Dougherty [3] indicated that culture involves learned and transmitted understanding about values, beliefs, rules of behavior and lifestyle practices that leads each group in their thinking and actions in patterned ways. Giger and Davidhizar [4] stated that transcultural nursing is a practice based on the differences and similarities between cultures in relation to health, health care, and illness, with consideration of patient values, beliefs, and practices. Further, culture develops over time as a result of imprinting the mind through social and religious structures and intellectual and artistic manifestations. The concept of ethnic culture has four basic characteristics: it is learned from birth through language and socialization; it is shared by members of the same cultural group, and it includes an internal sense and external perception of distinctiveness; it is influenced by specific conditions related to environmental and technical factors and to the availability of resources and it is dynamic and ever-changing.

Cultural diversity has also been defined in a number of ways. Often, skin color, religion, and geographic area are the only elements used to identify diversity, with ethnic minorities being considered the primary sources of cultural diversity. As stated earlier, however, there are several other possible sources of cultural diversity [2]. In addition, to truly acknowledge the cultural differences that may influence health care delivery, the nurse must acknowledge that his or her own cultural background carries an influence [5].

Copyright @ 2020: This is an open-access article distributed under the terms of the Creative Commons Attribution license which permits unrestricted use, distribution, and reproduction in any medium for non commercial use (NonCommercial, or CC-BY-NC) provided the original author and source are credited. 
Culturally competent nursing care has been defined as effective, individualized care that considers cultural values, is culturally aware and sensitive, and incorporates cultural skills [6, 5, 7]. Culturally competent care is a dynamic process that requires comprehensive knowledge of culture-specific information and an awareness of, and sensitivity to, the effect that culture has on the care situation. It requires the nurse to integrate cultural knowledge, awareness of his or her own cultural perspective, and the client's cultural perspectives into the plan of care [4]. Exploring one's own cultural beliefs and how they might conflict with the beliefs of the patients being cared for is the first step toward becoming culturally competent. Understanding the diversity within cultures, such as subcultures, is also important.

Transcultural nursing refers to a formal area of study and practice that focuses on the cultural care values, beliefs, and practices of individuals and groups from a particular culture [4]. The practice of transcultural nursing provides a culture-specific and culture-specific care which aims to promote health to all individuals across life span [4, 8]. When culturally appropriate care is provided, all individuals, and the community or institution at large, benefit. When a nurse provides care beyond his national boundaries, the term international or transnational nursing is often used.

Leininger [8] developed the Culture Care Diversity and Universality Theory. The goal of the theory is to provide culturally congruent nursing care to improve care for people of different or similar cultures. This means promoting recovery from illness, preventing conditions that would limit the patient's health or well-being, or facilitating a peaceful death in ways that are culturally meaningful and appropriate. Nursing care needs to be tailored to fit the patient's cultural values, beliefs, and lifestyle.

Leininger's theory includes providing culturally congruent nursing care (meaningful, beneficial, and satisfying health care tailored to fit the client's cultural values) through culture care accommodation and culture care restructuring. Culture care accommodation refers to "those professional actions and decisions that a nurse makes in his care to help people of a designated culture achieve a beneficial or satisfying health outcome". On the other hand, culture care restructuring or repatterning refers to "those professional actions and decisions that help patients reorder, change, or modify their lifestyles toward new, different, or more beneficial health care patterns". At the same time, the client's cultural values and beliefs are respected, and a better or healthier lifestyle is provided.

Giger and Davidhizar [4] created an assessment model to guide the nurse in exploring cultural phenomena that might affect nursing care. Their Transcultural Assessment Model was developed in response to the need for nursing students to assess and provide care for clients that were culturally diverse. The model includes six cultural phenomena: "communication, time, space, social organization, environmental control and biological variations". These guide the nurses for client assessment and from which culturally sensitive care can be designed. This model has been used in various patient care settings to provide data essential to the provision of culturally competent care.

Transcultural Assessment Model proposes a framework that facilitates assessment of the individual. A set of questions is constructed under each of the six areas to generate information useful in planning care congruent with the individual's cultural orientation and individual needs. The model also represents a learning tool that can be utilized to explore issues about any of the six broad areas in practice. It encourages flexibility and the involvement of the patient as an equal partner in the cultural assessment of needs. The model is useful in research and has been used in numerous studies.

Ludwig-Beymer [9] cited in a book, Creating Culturally Competent Organizations; that an individual's culture affects access to care and health-seeking behaviors, as well as perceived quality of care. Moreover, it is also essential to assess the culture of providers and organizations. Cultural barriers may occur in the interplay of client, provider, and organizational cultures. Furthermore, these barriers may cause conflicts which will lead to a client's lack of trust or reluctance to access services, and may ultimately result in health care inequities. Culturally competent health care is increasingly viewed as vital in preventing racial and ethnic disparities, improving health care quality, and controlling costs. The goal of transcultural nursing is to include the delivery of culturally competent care to individuals, families, groups, communities, and institutions. These transcultural nursing theories, concepts and models will guide nursing practice in various cultural health care settings across the life span. It stipulates that culturally competent nurses could provide quality health care services to individuals, families, groups, communities and institutions and expand the theoretical basis for using concepts from the natural and behavioral sciences and from humanities to provide culturally competent and culturally congruent nursing care.

The transcultural nursing knowledge base is expanded by the knowledge on cultures in the nurse's own service area, especially in relation to healthcare practices and beliefs; it will help the nurse prevent personal and biased assumptions on the client's culture and become aware his own biases and prejudices; and will help him learn new communication skills to simplify language for any client regardless of primary language. 


\section{REFERENCES}

1. Fabrigas, Y. C., \& Maniago, J. D. (2018). Ayta's indigenous healthcare practices: a descriptive-qualitative study. European Scientific Journal, 14(3), 408-426. http://dx.doi.org/10.19044/esj.2018.v14n3p408

2. Albougami A.S., Alotaibi J.S., Alsharari A.F., Albagawi B.S., Almazan J.U., Maniago J.D., Assiri, Z. A., \& Elrazkey, J. H. (2019). Cultural competence and perception of patient-centered care among expatriate nurses in Saudi Arabia: A cross-sectional study. Pakistan Journal of Medical and Health Sciences, 13(2), 933-938. http://www.pjmhsonline.com/2019/july_sep/pdf/933.pdf

3. Dougherty, M. (1979). Medical Anthropology Newsletter, 10(4), 23-25. www.jstor.org/stable/648185

4. Giger, J. N., \& Davidhizar, R. E. (1999). Transcultural nursing: Assessment and Intervention (3rd Ed.). St. Louis: C. V. Mosby.

5. Krumberger, J. M. (2000). Critical Care Close-Up. RN, 63(4), 24AC2-24AC3. https://www.elibrary.ru/item.asp?id=3949709

6. Hunter, J. L. (2008). Applying constructivism to nursing education in cultural competence: A course that bears repeating. Journal of Transcultural Nursing, 19(4), 354-362. https://doi.org/10.1177\%2F1043659608322421

7. Wilkinson, J. M. (2001). Nursing process and critical thinking. New Jersey: Prentice Hall.

8. Leininger, M. (2001). A mini journey into transcultural nursing with its founder. Nebraska Nurse, 34(2), 16-17. https://pubmed.ncbi.nlm.nih.gov/11998294/

9. Ludwig-Beymer, P. (2003). Creating culturally competent organizations. Transcultural Concepts in Nursing Care. 4th ed. Philadelphia: Lippincott Williams \& Wilkins, 249-271. 